\title{
COMPARISON OF EFFICACY OF EQUIPOTENT DOSES OF ADDITIVES: FENTANYL AND CLONIDINE WITH 0.5\% BUPIVACAINE INTRATHECALLY FOR GYNECOLOGICAL LAPAROSCOPIC SURGERIES
}

\author{
Pawan1, Chaitanya Kamath², Sowmya Rohith³, Sailakshmi M. P. A4 \\ ${ }^{1}$ Assistant Professor, Department of Anaesthesia, Rajarajeswari Medical College \& Hospital, Bangalore. \\ ${ }^{2}$ Assistant Professor, Department of Anaesthesia, JNMC Medical College \& Hospital, Belgaum. \\ ${ }^{3}$ Assistant Professor, Department of Anaesthesia, Bangalore Medical College. \\ ${ }^{4}$ Professor, Department of Obstetrics \& Gynaecology, Rajarajeswari Medical College \& Hospital, Bangalore.
}

\begin{abstract}
Spinal anesthesia for laparoscopic surgeries has been the new trend in anesthetic practice. Till date, the limiting factor for use of spinal anesthesia for laparoscopy was patient's discomfort due to shoulder tip pain. But with recent advances, addition of adjuvant to local anesthetics like fentanyl, clonidine, buprenorphine etc., not only provides effective anesthesia and prolongs postoperative analgesia, but also enhances patient comfort by attenuating shoulder pain. In our study, sixty ASA grade I/II patients scheduled for elective laparoscopic gynecological procedures under spinal anesthesia were divided into two groups of 30 each. The first group (Group A) received $3.3 \mathrm{ml}$ of hyperbaric $0.5 \%$, bupivacaine with $20 \mathrm{mcg}$ of fentanyl. The second group (Group B) received $3.3 \mathrm{ml}$ hyperbaric $0.5 \%$, bupivacaine with $30 \mathrm{mcg}$ of clonidine. From our study it was concluded that fentanyl or clonidine can be used as adjuvant for spinal anesthesia for laparoscopic surgeries, but with clonidine patients were more comfortable and hemodynamically stable with lesser incidences of shoulder tip pain.
\end{abstract}

KEYWORDS: Bupivacaine, Clonidine, Fentanyl, Intrathecal, Laparoscopy, Shoulder Tip Pain.

HOW TO CITE THIS ARTICLE: Pawan, Chaitanya Kamath, Sowmya Rohith, Sailakshmi M. P. A. "Comparison of Efficacy of Equipotent Doses of Additives: Fentanyl \& Clonidine with 0.5\% Bupivacaine Intrathecally for Gynecological Laparoscopic Surgeries." Journal of Evolution of Medical and Dental Sciences 2015; Vol. 4, Issue 93, November 19; Page: 15899-15902, DOI: $10.14260 /$ jemds/2015/2311.

INTRODUCTION: In our study, we recruited sixty patients scheduled for elective laparoscopic gynecological procedures under spinal anesthesia. They were divided into two groups of 30 each. The first group received $3.3 \mathrm{ml}$ of hyperbaric Bupivacaine with $20 \mathrm{mcg}$ of Fentanyl and the second group received hyperbaric Bupivacaine $3.3 \mathrm{ml}$ with $30 \mathrm{mcg}$ of Clonidine. There was no modification in the technique and the intraabdominal pressure was kept between $10 \mathrm{mmHg}$ to $12 \mathrm{mmHg}$. Sedation was given if required and conversion to general anesthesia was given to patients not responding to sedation or in whom adequate block was not obtained with spinal anaesthesia. The two groups were compared in terms of intraoperative haemodynamics, quality of spinal anesthesia and duration of postoperative analgesia, intra- and post-operative sedation, presence of shoulder tip pain, incidence of PONV and complications if any. We compared the two groups to assess the efficacy of the drugs chosen as a remedy for shoulder tip pain in laparoscopy. Any intraoperative respiratory discomfort due to positioning or pneumo-peritoneum was also considered for giving sedation.

METHODOLOGY: The present study was conducted after obtaining written, informed and valid consent. Approval from the institutional ethical committee was obtained for the study; 60 patients undergoing elective gynecological laparoscopic procedures.

Financial or Other, Competing Interest: None.

Submission 04-11-2015, Peer Review 05-11-2015,

Acceptance 09-11-2015, Published 19-11-2015.

Corresponding Author:

Dr. Sowmya Rohith,

Department of Anaesthesia,

Bangalore Medical College,

Bangalore.

E-mail:dr.soumyarohit@gmail.com

DOI:10.14260/jemds/2015/2311.
Sample size calculation was done using statistical software (Epi Info software, version 3.2) ASA Grade I and II patients were chosen and randomly divided into 2 groups: Group A-who received $0.2 \mathrm{ml}$ Fentanyl (25mcg) $+0.5 \%$ Bupivacaine $3.30 \mathrm{ml}$; Group B- who received $0.2 \mathrm{ml}$ Clonidine (30 mcg)+0.5\%, 3.3ml Bupivacaine.

\section{Inclusion Criteria Were as Follows:}

1. ASA grade I and II patients.

2. Age: $18-50$ years.

3. Surgery: Elective laparoscopic gynecologic procedures with estimated pneumoperitoneum time less than 90 min, e.g. laparoscopic ovarian cystectomy, laparoscopicassisted vaginal hysterectomy, diagnostic laparoscopy.

\section{Exclusion Criteria Were as Follows:}

1. ASA grade $>$ II.

2. Age: $<18$ or $>55$ years.

3. Patient's refusal.

4. Known contraindications to spinal anesthesia.

5. All patients were examined a day before surgery and were kept NPO overnight. They received inj.

Glycopyrrolate $0.2 \mathrm{mg}$ and inj. Ondansetron $4 \mathrm{mg}$ intravenously as premedication. In the operation theatre, patient's baseline pulse, blood pressure, saturation, $\mathrm{EtCO}_{2}$, respiratory rate, and ECG were recorded and all were preloaded with ringer lactate $15 \mathrm{ml} / \mathrm{kg}$. These patients were randomly assigned using a sealed envelope technique into two groups in a double-blind manner. Group A - who received $0.2 \mathrm{ml}$ Fentanyl $(25 \mathrm{mcg})+0.5 \%$ Bupivacaine $3.30 \mathrm{ml}$; Group B - who received $0.2 \mathrm{ml}$ Clonidine $(30 \mathrm{mcg})+0.5 \%$, $3.3 \mathrm{ml}$ Bupivacaine. 
Spinal anesthesia was given in a sitting position in L3-L4 interspace with 26-gauge Quincke's spinal needle. The anesthesiologist giving spinal anesthesia was blinded to the solution administered intrathecally. Patients were made supine and following parameters noted: Time of the onset of sensory block as assessed by pinprick, motor block assessed by using Bromage scale, time to achieve maximum sensory level (Upto T4) and the time if patient demanded rescue analgesia.

The operating table was adjusted to achieve a sensory level of $\mathrm{T} 4$ in all patients. Intraoperative pulse, $\mathrm{BP}, \mathrm{RR}, \mathrm{SPO}_{2}$, etCO $\mathrm{O}_{2}$ by a side stream capnometer placed at the nostril and ECG were monitored and noted at the time of induction, postinduction, during the creation of pneumoperitoneum, then every $15 \mathrm{~min}$ throughout the procedure and every $30 \mathrm{~min}$ post-operatively. Inflation pressure of $\mathrm{CO}_{2}$ during pneumoperitoneum was kept below $15 \mathrm{mmHg}$ in all cases.

Hypotension was defined as $>20 \%$ decrease in systolic blood pressure and was treated with intravenous fluids and ephedrine $6 \mathrm{mg}$ in incremental doses. Bradycardia $(\mathrm{HR}<$ $60 / \mathrm{min}$ ) was treated with intravenous atropine. Sedation was assessed using Ramsay scale and the score was maintained at 2-3. Intraoperative complaints of shoulder tip pain were noted and assessed using visual analogue scale (VAS). Scores between 1-6 were treated with Inj. Midazolam $1 \mathrm{mg}$ and Inj. Ketamine 25mg.

It was decided that VAS scores more than 7 or patients not responding to sedation or failed spinal anesthesia would be converted to general anesthesia. Adverse effects such as PONV were also recorded. Postoperative analgesia was given in the form of diclofenac sodium $75 \mathrm{mg}$ intravenous infusion. The time when patient demanded rescue analgesic was also recorded. The duration of spinal anesthesia was considered as that from the onset of sensory block to the administration of the rescue analgesic.

Data was analyzed using SPSS software version 20. It was expressed as mean +/-sd and Independent sample t test was used to analyze continuous data and chi square test for categorical variable. A P value of less than 0.05 is considered statistical significant.

RESULTS: A total of 60 patients undergoing elective laparoscopic surgeries under spinal anesthesia were enrolled in our study which were divided two groups in a double-blind manner. Group A - who received 0.2ml Fentanyl (20mcg) + $0.5 \%$ Bupivacaine $3.30 \mathrm{ml}$; Group B - who received $0.2 \mathrm{ml}$ Clonidine (30 mcg) + 0.5\%, 3.3ml Bupivacaine.

Both groups were comparable with respect to age and weight.

\begin{tabular}{|c|c|c|c|}
\hline \multicolumn{5}{|c|}{ DEMOGRAPHIC DATA OF PATIENTS UNDER STUDY } \\
\hline & $\begin{array}{c}\text { Group A } \\
\text { Mean SD }\end{array}$ & $\begin{array}{c}\text { Group B } \\
\text { Mean SD }\end{array}$ & P value \\
\hline Age(yrs) & $45.90+/ 5.294$ & $43.97+/ 5.951$ & .189 \\
\hline Weight(kg) & $64.35+/-8.229$ & $65.27+/ 8.311$ & .78 \\
\hline \multicolumn{4}{|c|}{ SD: Standard Deviation } \\
\hline \multicolumn{4}{|c|}{ Table 1: Demographic Data of Patients } \\
\hline
\end{tabular}

The onset of neuraxial block to T4 level is compared. The onset of T4 level was 9.4 mins (mean) in group A and 10.83 mins (mean) in Group B.
Though the mean time required to achieve T4 level was higher in Clonidine group, it was not statistically significant. Comparison of pulse rates between the two groups were done.

While it is expected that maximum variations to happen before and after creating pneumoperitoneum, it was noted that the fluctuations were more in group B (Series 2) than group A (Series 1). Group B recorded lowest fall of 64/, min. The difference in pulse rates between the two groups was just statistically significant with a P-value of 0.03 . None of the patients in either group needed atropine.

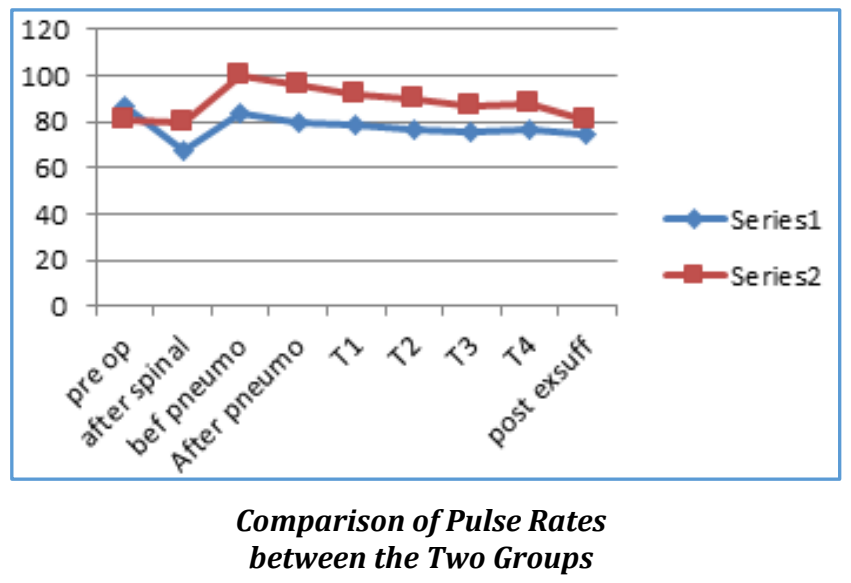

Blood pressure variations were also tabulated. In both the groups BP increased after the creation of pneumoperitoneum with the mean value of $136 / 90 \mathrm{mmHg}$ in group A and 124/80mmHg in group B. However, later in the intraoperative period, there was a fall in BP in both the groups. Rest of the BP changes in the intra- and postoperative period were comparable.

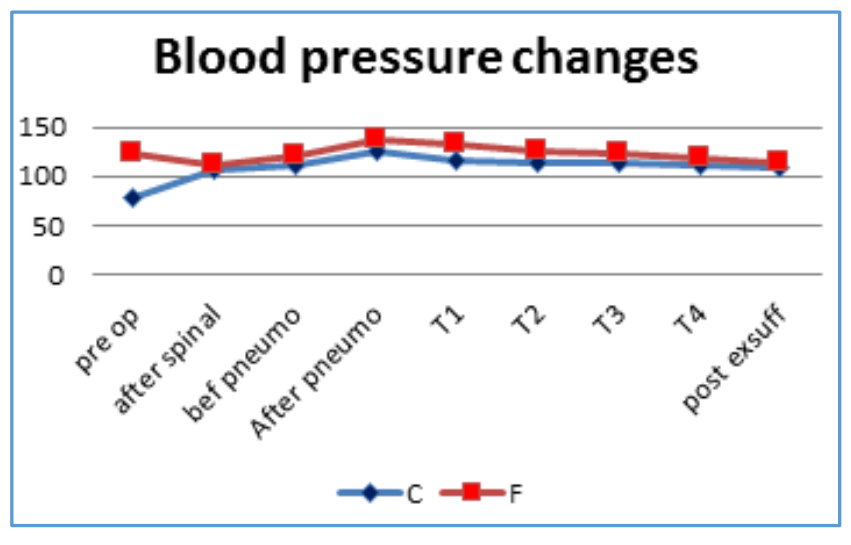

Comparison of blood pressure
changes between the 2 groups

$\mathrm{EtCO}_{2}$ increased in response to pneumoperitoneum in both the groups and changes were comparable (P-value 1.00). Oxygen saturation and ECG were normal in both the groups throughout the procedure and post-operatively. The duration of spinal anesthesia was considered as that from the onset of sensory block (T4) to the administration of the rescue analgesic. The mean duration in group A $234.87 \mathrm{mins}$ +/- 5.686 when compared to group B which was 300.87 mins $+/-9.179$. In our study, Clonidine significantly prolongs the duration of spinal anesthesia thus extending the analgesia as indicated by delayed demand for rescue analgesia in the postoperative period. 
Shoulder tip pain is the most important parameter while assessing the patient's comfort during spinal anesthesia in laparoscopic surgeries. In our study, 17 patients in Group A had shoulder tip pain and sedation and analgesia for obviating discomfort, while only 2 patients in Group B had such pain.

\begin{tabular}{|c|c|c|}
\hline \multicolumn{3}{|c|}{$\begin{array}{c}\text { INCIDENCE OF SHOULDER TIP PAIN(STP) AND } \\
\text { ADMINISTRATION OF RESCUE ANALGESIC }\end{array}$} \\
\hline & Group A & Group B \\
\hline STP & 17 & 2 \\
\hline $\begin{array}{c}\text { Rescue Analgesia } \\
\text { given }\end{array}$ & 19 & 2 \\
\hline \multicolumn{2}{|c|}{$\begin{array}{c}\text { Table 2: Incidence of shoulder tip pain } \\
\text { and administration of rescue analgesic }\end{array}$} \\
\hline
\end{tabular}

These data were analyzed by chi-square analysis corrected by the Yates method and the difference in complaints of shoulder tip pain as well as sedation-analgesia requirements in both groups were found to be statistically significant. Incidence of postoperative nausea and vomiting was significantly high in Group A compared to Group B.

\begin{tabular}{|c|c|c|}
\hline & Group A & Group B \\
\hline Yes & 28 & 12 \\
\hline No & 2 & 22 \\
\hline Table 3: Post-operative nausea and vomiting \\
\hline
\end{tabular}

DISCUSSION: Regional anesthesia for laparoscopic surgeries is a newer trend that provides optimal anterior abdominal wall relaxation, conscious, receptive patient, cost effectiveness and preventing the potential problems of general anesthesia.1,2 The pneumoperitoneum-induced rise in intraabdominal pressure including pressure on the diaphragm and carbondioxide-induced peritoneal irritation are factors to be considered. ${ }^{3}$ Hemodynamic changes are evident due to pneumoperitoneum and all considerations have to give the response during anesthesia.1,3

Shoulder tip pain is one of the leading causes of conversion to general anesthesia in patients. This pain is strongly associated with the occurrence of pneumoperitoneum. ${ }^{4}$ Pneumoperitoneum-induced shoulder tip pain is mainly attributable to diaphragmatic and peritoneal irritation from carbondioxide, mediated by the phrenic and cervical spinal nerves. ${ }^{4}$ with effective adjuvant and decrease in the intra-abdominal pressures. Shoulder tip pain can be combated with good degree of patient comfort. ${ }^{5}$

Our present study compares the efficacy between Fentanyl and Clonidine as intrathecal additives in spinal anesthesia for laparoscopic surgery. This study showed better hemodynamic stability with significant reduction in shoulder tip pain when Clonidine was added to hyperbaric Bupivacaine under spinal anesthesia in comparison to Fentanyl. Also, there was prolongation of duration of postoperative analgesia with decreased incidences of postoperative nausea and vomiting with Clonidine as adjuvant.

The present study showed a significant reduction in shoulder tip pain in the group B receiving Clonidine in addition to hyperbaric Bupivacaine under spinal anesthesia.

The reduction in shoulder tip pain can be explained as follows: Clonidine is a selective alpha 2 agonist and acts by inhibiting norepinephrine release from presynaptic terminals. ${ }^{6,7}$ It produces sedation and analgesia by its action on spinal cord and locus coeruleus analgesia that is produced by clonidine is not only because of sympatholysis at peripheral level, but also due to decrease catecholamine release in brain. This results in an overall analgesic effect of clonidine. Also, it has been shown that intrathecal clonidine suppresses tumor necrosis factor in plasma and CSF during the perioperative period which is presumed to result in analgesia.

It also acts on imidazoline receptors compounding the analgesic effects of Clonidine.6,7 These factors may be responsible for decreasing the shoulder tip pain in laparoscopy. ${ }^{7}$ Due to its multireceptor level action, the efficacy of analgesia is superior when compared to fentanyl. The reduction in shoulder tip pain when fentanyl seen in some cases may be explained by neurally mediated action of the drug. ${ }^{8}$ Reports have shown that opiods administered was detectable in the cisterna magna within 30 min after lumbar intrathecal administration and was redistributed within the cerebrospinal fluid (CSF). ${ }^{8,9}$

In the present study, shoulder tip pain regardless of the occurrence of pneumoperitoneum was easily managed with intravenous ketamine. Ketamine has potent analgesic and sedative effects while maintaining protective airway reflexes and minimal respiratory depression and often increases blood pressure and heart rate. ${ }^{10}$ Ketamine was therefore the choice of analgesic agent in the present study, in which a small initial dose $(0.5 \mathrm{mg} / \mathrm{kg})$ and subsequent incremental use (up to $1 \mathrm{mg} / \mathrm{kg}$ ) provided effective control of shoulder tip pain without cardiovascular complications. ${ }^{10,11}$

Intrathecal clonidine has been shown to prolong the action of spinal anesthesia when added to local anesthetic due to its multireceptor level action and also helps in providing better post-operative analgesia after intrathecal use when compared to fentanyl.6,7 The sedation provided by Clonidine is excellent as elicited by the Ramsay sedation score, thereby decreasing the need of additional intravenous drugs. The combined property of sedation and analgesia of clonidine keeps patients pain free and comfortable.

This therefore obviates unnecessary intravenous interventions, thus serving the purpose of spinal anaesthesia.7,12 As seen in our study, patients receiving intrathecal Clonidine had prolonged post-operative analgesia and delayed requirement of rescue analgesia. Sympatholytic effects of intrathecal clonidine resulting in hypotension are seen with higher doses forcing the use of vasopressors. ${ }^{7,12}$ In our study, we found that a low dose of intrathecal clonidine of $30 \mathrm{mcg}$ does not result in worrisome hypotension.

This can be attributed to the low dose used and also to the increased peripheral vascular resistance after pneumoperitoneum creation, which counteracts the fall in blood pressure. However, bradycardia does occur with this dose, but hardly required any treatment. With the results obtained in the present study, in which the incidence of hypotension in the experimental group was significantly lower than that in the control group $(P=0.009)$. However, hypotension was easily corrected without complications by intravenous administration in both groups.

Intra- and post-operative use of intravenous opioids increase the risk of PONV and postoperative nausea and vomiting (PONV) is among the most troublesome postoperative side-effects and reduces patients' compliance to the procedure.13,14 
In our study it was clearly demarcated that fentanyl caused PONV, whereas Clonidine group had markedly reduced PONV.

CONCLUSION: From this study, we do recommend the usage of spinal anesthesia with low dose additives for short duration laparoscopic surgeries with intra-abdominal pressures of $10-12 \mathrm{~mm}$ of $\mathrm{Hg}$, as an alternative for general anesthesia. Adjuvant Clonidine provides superior quality analgesia with sedation obviating the usage of additional drugs. However, in any case of patient discomfort despite rescue analgesics the anesthetist must be well prepared for conversion to conventional techniques.

\section{REFERENCES:}

1. Smith I. Anesthesia for laparoscopy with emphasis on outpatient laparoscopy. Anesthesia Clin North Am. 2001; 19:21-41.

2. O'Malley C, Cunningham A. Physiology changes during laparoscopy. Anesthesiol Clin North Am. 2001; 19:1-19.

3. Gutt $\mathrm{CN}$, Oniu $\mathrm{T}$, Mehrabi $\mathrm{M}$ et al. Circulatory and respiratory complications of carbon dioxide insuflation. Dig Surg. 2004; 21:95-105.

4. Clinical effects of intrathecal fentanyl on shoulder tip pain in laparoscopic total extraperitoneal inguinal hernia repair under spinal anaesthesia: A double-blind, prospective, randomized controlled trial Tae-Yun Sung1 journal of international medical research Dec 2013 41(6).

5. Sarli L, Costi R, Sansebastiano G. Prospective randomized trial of low pressure pneumoperitoneum for reduction of shoulder tip pain following laparoscopy. Br J Surg. 2000;87:1161-5.
6. Kaabachi O, Zarghouni A, Ouezini R, Abdelaziz AB, Chattaoui O, Kokki H. Clonidine $1 \mathrm{microg} / \mathrm{kg}$ is a safe and effective adjuvant to plain bupivacaine in spinal anesthesia in adolescents. Anesth Analg. 2007;105: 516-9.

7. Eisenach JC, De Kock M, Klimscha W. Alpha (2)adrenergic agonists for regional anesthesia. A clinical review of clonidine (1984-1995) Anesthesiology. 1996; 85:655-74.

8. Vaghadia H, McLeod DH, Mitchell GW, Merrick PM, Chilvers CR. Small-dose hypobaric lidocaine-fentanyl spinal anesthesia for short duration outpatient laparoscopy. I. A randomized comparison with conventional dose hyperbaric lidocaine. Anesth Analg. 1997; 84:59-64.

9. Eisenach JE. Lipid soluble opioids do move in cerebrospinal fluid. Reg Anesth Pain Med 2001; 26: 296-297.

10. Kohrs R, Durieux ME. Ketamine: teaching an old drug new tricks. Anesth Analg 1998; 87: 1186-1193.

11. Zielmann S, Kazmaier S, Schnüll S, et al. S-(+)-ketamine and circulation. Anaesthesist 1997; 46(Suppl 1)S43S46.

12. Sood Jayashree, Kumra VP. Anesthesia for laparoscopic surgery. IJS. 2003;65:232-240.

13. Sinha R, Gurwara AK, Gupta SC. Laparoscopic surgery using spinal anesthesia.JSLS. 2008; 12:133-8.

14. Apfel CC, Läärä E, Koivuranta $M$, et al. A simplified risk score for predicting postoperative nausea and vomiting: conclusions from cross-validations between two centers. Anesthesiology 1999; 91: 693-700. 